\title{
On Feasibility of Autonomous Frequency-Support Provision From Offshore HVDC
} Grids

Bidadfar, Ali; Saborío-Romano, Oscar; Sakamuri, Jayachandra N.; Cutululis, Nicolaos Antonio; Akhmatov, Vladislav; Sorensen, Poul E.

Published in:

IEEE Transactions on Power Delivery

Link to article, DOI:

10.1109/TPWRD.2020.2971559

Publication date:

2020

Document Version

Peer reviewed version

Link back to DTU Orbit

Citation (APA):

Bidadfar, A., Saborío-Romano, O., Sakamuri, J. N., Cutululis, N. A., Akhmatov, V., \& Sorensen, P. E. (2020). On Feasibility of Autonomous Frequency-Support Provision From Offshore HVDC Grids. IEEE Transactions on Power Delivery, 35(6), 2711-2721. https://doi.org/10.1109/TPWRD.2020.2971559

\section{General rights}

Copyright and moral rights for the publications made accessible in the public portal are retained by the authors and/or other copyright owners and it is a condition of accessing publications that users recognise and abide by the legal requirements associated with these rights.

- Users may download and print one copy of any publication from the public portal for the purpose of private study or research.

- You may not further distribute the material or use it for any profit-making activity or commercial gain

- You may freely distribute the URL identifying the publication in the public portal 


\title{
On Feasibility of Autonomous Frequency-Support Provision from Offshore HVDC Grids
}

\author{
Ali Bidadfar ${ }^{\mathbb{D}}$, Oscar Saborío-Romano ${ }^{\mathbb{D}}$, Jayachandra N. Sakamuri ${ }^{\mathbb{D}}$, Nicolaos A. Cutululis ${ }^{(\mathbb{D})}$, \\ Vladislav Akhmatov, Poul E. Sørensen (D)
}

\begin{abstract}
Offshore multi-terminal high-voltage dc (HVDC) grids are emerging as a technical reliable and economical solution to transfer more offshore wind energy to inland power grids. It is also envisaged that the offshore HVDC grids pave the way for both offshore wind participation and sharing inland frequency reserves for efficient power systems' frequency control. The frequency control mechanism in an HVDC grid can be either centralized or decentralized. An autonomous frequency control (AFC) is a decentralized control, which does not require communication links between dc grid terminals. In the AFC, the dc-link voltage is used as a medium to reflect the inland frequency change to other terminals. The AFC has some technical and nontechnical challenges, especially when the dc grid is connected to more than one shore ac systems. Among challenges of the AFC are the deficiency in meeting grid code requirements, adverse reaction of converters, dc voltage variations, difficulties of offshore wind participation in power markets. This paper proposes a new methodology of frequency control which uses both centralized control and AFC simultaneously. The proposed methodology shall improve system security and mitigate the listed problems of the AFC. A four-terminal de grid is described and used for analysis and demonstration of the proposed methodology.
\end{abstract}

Index Terms-HVDC grids, frequency control, offshore wind, power system

\section{INTRODUCTION}

W ITH increasing penetration of intermittent renewables in power systems, the technical and regulatory feasibility of such generations in providing frequency support has attracted attention. To take part in the frequency control, a generator shall bid reserve capacity in electricity markets. The traded capacity can be frequency containment reserve (primary) and/or frequency restoration (secondary) reserve. Provision of frequency control and restoration support has become a requirement for all generation types, including wind power plants [1]. Therefore, many experiments and researches are conducted to investigate and demonstrate the participation of wind power in the frequency control. In a pilot conducted at a $21 \mathrm{MW}$ wind farm in west Denmark [2], the production has been decreased by $5 \%$ to provide downward regulation. In [3], a Belgian pilot for using an $81 \mathrm{MW}$ wind farm to provide frequency restoration reserve has been conducted, and its feasibility has been investigated from technical and regulatory points of view.

The promised reserve must be activated when needed. Otherwise, besides penalizing the generator, the system security could be on risk. Therefore, from the technical point of view,

This work has received funding from the European Union's Horizon 2020 research and innovation programme under grant agreement No 691714 . the reliability of frequency-support mechanism must be high, especially for the primary type, which prevents frequency dropping beyond the limits. To increase the reliability of frequency support from high voltage dc (HVDC) connected offshore wind farms, an autonomous frequency control (AFC) scheme, without using communication links between onshore and offshore stations, has been proposed in [4]. In this control, offshore frequency mirrors the land frequency by modulating the dc link voltage.

Some studies have been carried out on implementing the autonomous [communication free] frequency support from offshore multi-terminal dc (HVDC) networks [5]-[13] . In offshore HVDC grids, the shore converters are equipped with frequency droop control which transforms frequency deviations to dc voltage variations. Converters on the other ends (offshore wind and/or other land ac systems) react to dc voltage-change by regulating their active power. As a result, an AFC mechanism is established in the system. The impact of AFC on small-signal dynamics of offshore HVDC grids and onshore power systems has been studied in [13] and [14]. In [14], it has been concluded that AFC does not affect the dynamics of HVDC systems. In [13] and [15], it has been shown that frequency support can improve the onshore power systems' interarea modes. Although this method of frequency support is relatively more reliable and economical, it can result in some challenges, especially in terms of satisfying grid code requirements related to frequency control [16], [17] . In [6] it has been shown that using AFC in offshore HVDC grids, the delivered power to the land system, in response to a frequency drop, is less than what is required by grid codes. A compensation method has been proposed to mitigate the problem [6]. As presented in this paper, applying the compensation method is not straightforward when the dc grid operates with autonomous power-sharing control. Proper selection of voltage and frequency droop gains as well as interacting with dc voltage protection system are other probable challenges of using AFC [4].

There are other concerns of implementing AFC on offshore HVDC networks that have not been addressed in the literature. The main contribution of this paper is to analytically investigate the concerns challenging the feasibility of autonomous frequency support from offshore HVDC grids. The identified problems are incapability in delivering the expected power, inaccurate power-sharing among converters, dc voltage deviations, high dead-band in overall frequency control, undesired power flow in ac and dc lines, and inadaptability with different dc voltage control schemes. 
In this paper, a comprehensive control scheme for frequency support from offshore HVDC grids is proposed. The proposed control scheme uses AFC in parallel with centralized frequency control (CFC), which is embedded in the HVDC supervisory control. The CFC manages the power flow based on grid code requirements, electricity market schedules, lines and converters limits, availability of components as well as other conditions and requirements. When activating the CFC, the AFC is inherently nullified. Under contingencies, such as communication failure (to cause CFC not operational) and converter outage, the AFC assists the system security by a fast reaction.

The rest of the paper is organized as follow. In Section II HVDC grid model and control of converters are introduced. Challenges associated to AFC are detailed in Section III and proposed control scheme is presented in Section IV. Section $\mathrm{V}$ shows the simulations results, and the study is concluded in Section VI.

\section{HVDC GRID MODEL AND CONTROL SYSTEMS}

The offshore HVDC network model and its control, and also assumptions made in modeling and simulations are presented in this section.

\section{A. HVDC Grid Model}

The dc grid topology is shown in Fig. 1. It has two offshore wind farms and two onshore ac systems. Each of the shore systems is modeled as an aggregated synchronous machine equipped with a turbine and governor. The wind farms are modeled as IEC type-4 (fully-rated) wind turbines using the aggregation method given in [18]. The offshore C and D have 1000 and $800 \mathrm{MW}$ generation capacity. Frequency in all offshore and onshore ac networks is $50 \mathrm{~Hz}$. Modular multilevel converters (MMCs) are used for HVDC connections. The model used for MMCs is an average model of half-bridge type converter with 200 submodules per arm and $\pm 320 \mathrm{kV}$ of the dc-link voltage. The dynamics of MMC and its current and voltage controllers can be neglected when analytically studying the primary frequency control [13], [15]. Since the AFC, in comparison, has slower dynamics (rise-time is within the range of few hundred milliseconds), it is not expected to have a significant impact of MMC dynamics with an inner current control rise-time of few milliseconds, and voltage control of tens of milliseconds [19], [20]. Moreover, in [14], it has been concluded that frequency control does not affect the small-signal stability of offshore HVDC grids. This fact has also been observed in the simulations of this paper, where the MMCs have been modeled with full details. Nevertheless, the frequency control parameters, which are mainly frequency droops, are determined so that to satisfy the grid codes related to the frequency control.

The control and component parameters of the MMCs are given in the Appendix.

\section{B. HVDC Grid Control}

An HVDC grid control can be implemented in different ways [21]. Master-slave control: One converter controls the dc voltage and other converters active power. Without welldefined redundancy procedure, this control method suffers from low reliability under forced converter outage [21]. Voltage margin control: Similar to the master-slave control, one converter maintains the dc voltage while there are other converters providing backup to control the dc voltage in the case when the slack converter fails [22]. Autonomous power sharing: The dc voltage control is distributed among some converters using power-voltage droop action. In the case of dc voltage change, the consequent power deviation is autonomously shared among those converters equipped with droop control. This concept is similar to power-frequency droop in ac power systems. In this paper, the autonomous power sharing control is used for studies.

To implement the AFC, the onshore frequency deviation must be converted to a voltage- or power-change, depending on the type of the converter control. When using autonomous power sharing on both the shore converters, shown in Fig. 1, the frequency deviation can be included in their control as

$$
\begin{aligned}
& P_{1}=P_{1}^{*}+k_{\mathrm{v} 1} \Delta V_{\mathrm{D} 1}-k_{\mathrm{f} 1} \Delta f_{1} \\
& P_{3}=P_{3}^{*}+k_{\mathrm{v} 3} \Delta V_{\mathrm{D} 3}-k_{\mathrm{f} 3} \Delta f_{3}
\end{aligned}
$$

where $k_{\mathrm{v}}$ and $k_{\mathrm{f}}$ are respectively the inverse of voltage and frequency droops. The $\Delta$ sign indicates the measured value minus the reference value, e.g., $\Delta f_{1}=f_{1}-f_{1}^{*}$. All parameters with asterisk $(*)$ represent the reference values.

The AFC requires the offshore converters to measure the dc voltage deviation and convert it into offshore frequencychange. In Fig. 1, if both offshore farms have reserve capacity and intend to contribute in AFC, their frequencies are respectively changed as $\Delta f_{2}=R_{2} \Delta V_{\mathrm{D} 2}$ and $\Delta f_{4}=R_{4} \Delta V_{\mathrm{D} 4}$. The wind farms regulate their power supply in response to offshore frequency deviations as

$$
P_{2}=P_{2}^{*}-k_{\mathrm{f} 2} \Delta f_{2}, \quad P_{4}=P_{4}^{*}-k_{\mathrm{f} 4} \Delta f_{4} .
$$

As (3) shows, the power generated from offshore wind can be changed in the case of onshore frequency deviations. This is a foundation of AFC mechanism in an HVDC grid.

\section{Challenges Associated with AFC}

In this section some challenges of using AFC in offshore HVDC are identified and investigated.

\section{A. Incomplete Power Delivery to the Shore}

It has been shown in [6], [23], that using AFC in offshore HVDC, the expected power cannot be delivered to a disturbed onshore ac system. In [6], it is assumed that several OWFs are connected to one onshore power system via an offshore HVDC grid. For such a connection, a compensation has been proposed for incomplete power delivery. In this section, it is shown that the compensation, proposed in [6], is challenging in the case there are more than one onshore power systems. Assume that a generation unit trips in onshore A, in Fig. 1, and results in its frequency drop. A transfer function between frequency deviation, $\Delta f_{1}$, and the amount of power change in terminal $\mathrm{A}$, i.e., $\Delta P_{1}$., gives the required amount of power 


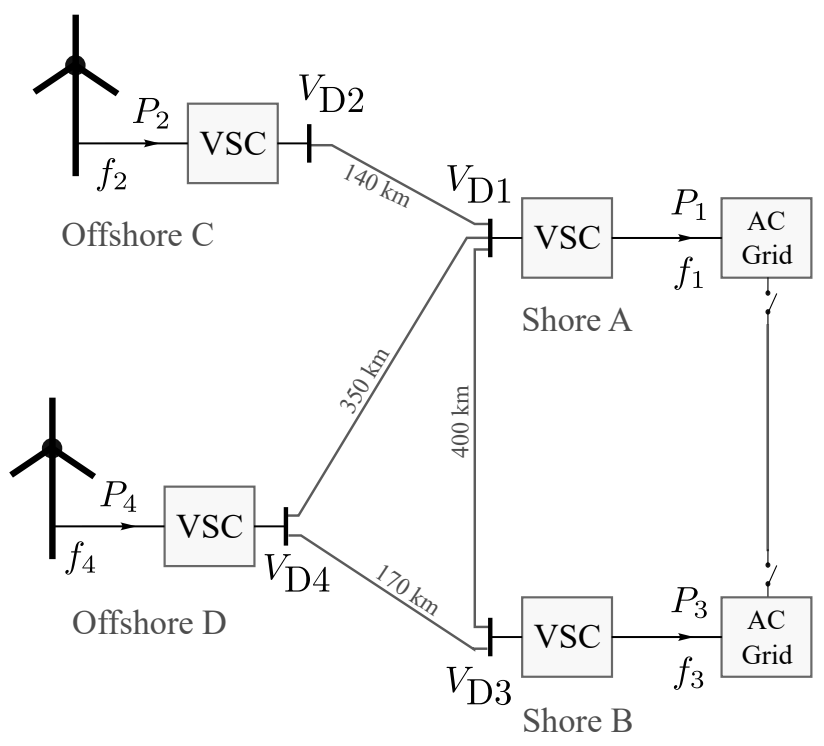

Fig. 1. The schematic diagram of the offshore HVDC grid used for studies.

delivered to system A. The transfer function is derived under the following assumptions. Both the converters on the shore use the dc voltage and frequency droop controls as stated in (1) and (2). The onshore grids are considered as separated with no ac link in between. Only the offshore substation $\mathrm{C}$ contributes to the frequency control. The dead-bands of the controllers and the dc network losses are negligible. Considering these assumptions results in $\Delta P_{2}=\Delta P_{1}+\Delta P_{3}$ and $V_{\mathrm{D} 1}=V_{\mathrm{D} 2}=$ $V_{\mathrm{D} 3}=V_{\mathrm{D} 4}$. When frequency drops on shore $\mathrm{A}$, the de link voltage is decreased based on (1). Both shore B and offshore $\mathrm{C}$ respond to the voltage drop by changing their active power as

$$
\Delta P_{2}=k_{\mathrm{v} 2} \Delta V_{\mathrm{D} 2}, \quad k_{\mathrm{v} 2}=k_{\mathrm{f} 2} R_{2} .
$$

The HVDC converter on shore B also changes its power in response to the dc voltage deviation.Since this converter feeds into the ac grid $\mathrm{B}$, its power-change may result in the grid frequency deviation, i.e., $\Delta f_{3}$, which activates the governors of the system B generators. Considering the aggregated damping ratio, $D_{3}$, and governor droop, $R_{\mathrm{g} 3}$, of shore $\mathrm{B}$, its frequencyand power-change after transients can be stated as

$$
\Delta f_{3}=\frac{1}{D_{3}+k_{\mathrm{g} 3}} \Delta P_{3}, \quad k_{\mathrm{g} 3}=1 / R_{\mathrm{g} 3} .
$$

Inserting (4) and (5) in (1), considering the made assumptions, results in

$$
\Delta P_{1}=-\underbrace{\frac{1}{1+k_{\mathrm{v} 1} \frac{1}{k_{\mathrm{v} 2}+k_{\mathrm{v} 3}\left(1+k_{\mathrm{f} 3}\left(D_{3}+k_{\mathrm{g} 3}\right)^{-1}\right)^{-1}}}}_{\text {Attenuation factor }} k_{\mathrm{f} 1} \Delta f_{1}
$$

where the attenuation factor is less than unit and it makes the delivered power, $\Delta P_{1}$, become less than what is expected, $\Delta P_{\exp }=-k_{\mathrm{f} 1} \Delta f_{1}$, by the relevant grid code. Because of two reasons, it is not easy to compensate the attenuation factor via multiplying its reverse by $k_{\mathrm{f} 1}$ as proposed in [6]. Firstly, both onshore frequency controls cannot be compensated at the same time since there is a reciprocity between them. Second, even in compensating for one onshore, the parameters of another ac system, e.g., $D_{3}, k_{\mathrm{g} 3}$ cannot be easily estimated. The transfer function of (6) will become more complex and difficult for analysis if offshore D also takes part in the AFC; though the attenuation factor will become smaller than the one obtained in (6).

\section{B. Inability to Provide Primary Reserve}

If an individual offshore wind farm becomes a primary reserve provider to support the shore frequencies, it should be able to export the expected power to the promised shore grid, e.g., shore A. With the same way as derived in (6), a transfer function between offshore $\mathrm{C}$ frequency, $\Delta f_{2}$, and shore A frequency, $\Delta f_{1}$ can be obtained as

$$
\Delta f_{2}=\frac{R_{2} k_{\mathrm{f} 1}}{k_{\mathrm{v} 1}+k_{\mathrm{v} 2}+k_{\mathrm{v} 3} \frac{1}{1+k_{\mathrm{f} 3}\left(D_{3}+k_{\mathrm{g}}\right)^{-1}}} \Delta f_{1}
$$

which shows that using AFC, it is not easy for offshore wind to accurately estimate the frequency deviation on the land system. The Danish grid code, for instance, requires the frequency measurement to have tolerance less than $+/-10 \mathrm{mHz}$, which according to (7) cannot easily be met by AFC because the control parameters and other ac system parameters, $k_{\mathrm{f} 3}, D_{3}$ and $k_{\mathrm{g} 3}$, are not necessarily fixed and $\Delta f_{2}$ cannot be linearly depending on $\Delta f_{1}$. The derived transfer function will become more complex in terms of parameterization of the dc network resistances, dead-bands, limits, and accepted accuracy of the offshore wind contribution to provide an adequate frequency accuracy. AFC is not suitable for accurate estimation of the shore frequency deviation. Further, AFC is not suitable for transmission of the required power flow to a specific onshore because of the autonomous power sharing control of the onshore converters. Therefore, using AFC, an individual HVDC-connected wind farm cannot provide adequate primary reserve.

\section{Inaccurate Power Control of OWFs with AFC}

Enabling an OWF to participate in AFC, its converter must be equipped with voltage-frequency droop, which creates negative feedback to the active power setpoint of the OWF. As shown in Fig. 2, the feedback is taken from the dc-link voltage deviation $\Delta V_{\mathrm{D}}=V_{\mathrm{D}}-V_{\mathrm{D}}^{*}$, which means that $V_{\mathrm{D}}^{*}$ is needed. Because of dc grid impedance [24], the dc-link voltage setpoints differ from terminal to another. The offshore voltage setpoint, $V_{\mathrm{D}}^{*}$, can be obtained either from solving power flow equations or, it can be set as the nominal voltage of the dc link. In the former case, the reference value must be updated based on scheduled power flow; this method seems to be an appropriate approach for the frequency control purpose, but it relies on communication links between the grid supervisory control and different terminals. In the latter, a relatively large dead-band should be considered for offshore voltage deviation to not activate the AFC under normal operations of onshore converters. For example when the distance between the land ac systems is far and they intend to change power flow between their converters, a relatively high voltage-change is needed. 


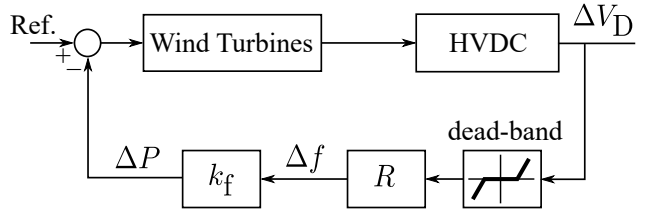

Fig. 2. Wind farm power-change based on dc voltage deviations on HVDC terminals.

This can be further explained by Fig. 2 which shows that offshore wind power production will change if the voltage deviation, $\Delta V$ exceeds the dead-band limits. If the dead-band is small, under normal operation, when the dc grid changes its operation from one point to another, the voltage deviation on the offshore terminals will act as negative feedback to power production, which can cause an inaccurate power control and also an interaction between wind farms. On the other hand, if the dead-band is too large, the overall dead-band experienced by AFC will be unacceptably large, and consequently, the response to onshore frequency deviation will not be efficient.

\section{Adopting Maximum Allowable Voltage Drop}

There should be alignment between the maximum allowable frequency drop and the maximum allowable dc voltage drop. The maximum allowable frequency drop can be extracted from the lowest frequency that an HVDC converter should stay connected [25]. Choosing the maximum allowable dc voltage deviation is not straightforward. If it is decided to be high, via $k_{\mathrm{v} 1}$, and $k_{\mathrm{v} 3}$, the dc grid dynamic can be affected [26]. On the other hand, if the voltage drop is chosen to be small, on the offshore side the voltage-frequency droop, $R$, and/or WTs' power-frequency bias, $k_{\mathrm{f}}$, should be high. This makes the wind farms sensitive to any small change on the dc link voltage, which might not be necessarily caused by AFC.

\section{E. Different Response to Different Onshore Frequencies}

If the shore converters use unequal voltage and frequency droops, i.e., $k_{\mathrm{v} 1} \neq k_{\mathrm{v} 3}$ and/or $k_{\mathrm{f} 1} \neq k_{\mathrm{f} 3}$, the same frequency deviation on the shore ac systems will result in different $\mathrm{dc}$ voltage-change. Therefore, the AFC reacts differently to the same frequency disturbance in different shore systems.

\section{F. Frequency Droop is not Linear}

Primary frequency control is a proportional control which does not have a single fixed droop gain for the entire range of frequency deviation. As an example, the Danish grid code requires frequency control for wind farms with four different droops, as shown in Fig. 3. Not having a single frequency droop implies that $k_{\mathrm{f} 1}, k_{\mathrm{f} 3}$, and $k_{\mathrm{g} 3}$ do not have a unique value. This fact makes the transfer function derived in (6) to be nonlinear (piece-wise linear) and almost impossible to compensate for the deficiency of AFC as suggested in [6]. The nonlinearity of the primary control makes the AFC even more complicated since the different terminals do not have access to instant frequency droop of the disturbed land system.

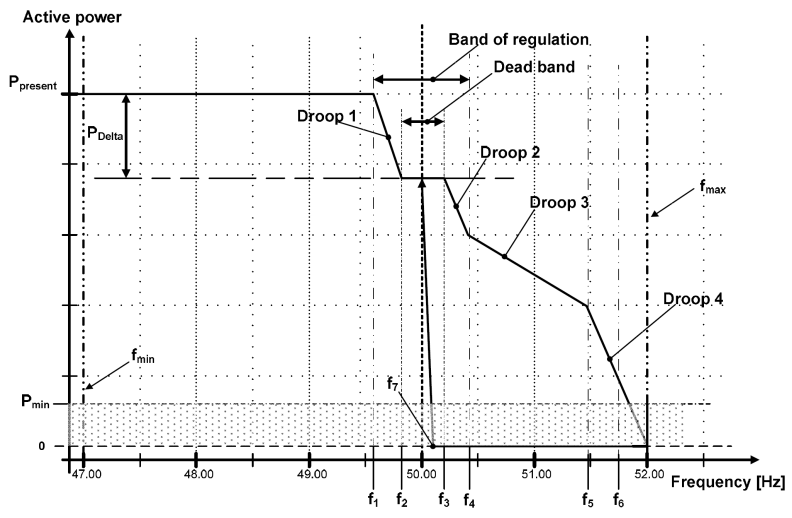

Fig. 3. Frequency control for wind generation, with various droops in different frequency ranges [27].

\section{G. Inconsistency with Different Voltage Control}

Implementing the AFC in a dc grid which, uses masterslave control or voltage margin control, causes all the required power to be exported from the voltage controlling terminal. In the case of master-slave control, the dc voltage controlling converter (master) maintain the dc voltage to the nominal value which, means that the frequency supportive power cannot be shared amongst different terminals (power resources). In the case of voltage margin control when the dc voltage shifts from one point to another, the power resource for AFC also changes and, this creates a problem for marketing the reserve capacity.

\section{H. Difficulties in Participating in Different Markets}

To implement the AFC, offshore wind farms regulate their power concerning the dc voltage-change. Every onshore system can cause the voltage-change. If each shore system has its own electricity market, the offshore wind cannot bid the primary reserve to an individual market using the AFC. The ENTSO-E (European network of transmission operators for electricity) grid code in [25] (Article 39.1.b) requires that offshore wind should implement a coordinated frequency control when it connects to a dc grid with more than one control area. This requirement can be met only by measuring the frequency from each control area, and not by measuring dc voltage deviation. Therefore, the AFC cannot meet the grid code requirement.

\section{Power Circulation Among Shore Converters}

In case of ac interconnection between inland systems (ac line is connected in Fig. 1) both ac systems will have the same frequency, i.e., $\Delta f_{1}=\Delta f_{3}=\Delta f$. The supportive power from offshore is shared between shore converters using the AFC. Assume that the frequency control loop is activated only for converter A, i.e., $k_{\mathrm{f3}}=0$ and only offshore $\mathrm{C}$ participates in the frequency support. Using $\mathrm{AFC}$, the power-change in offshore $\mathrm{C}$ can be stated as

$$
\Delta P_{2}=\frac{-k_{\mathrm{v} 2} k_{\mathrm{f} 1}}{k_{\mathrm{v} 1}+k_{\mathrm{v} 2}+k_{\mathrm{v} 3}} \Delta f
$$




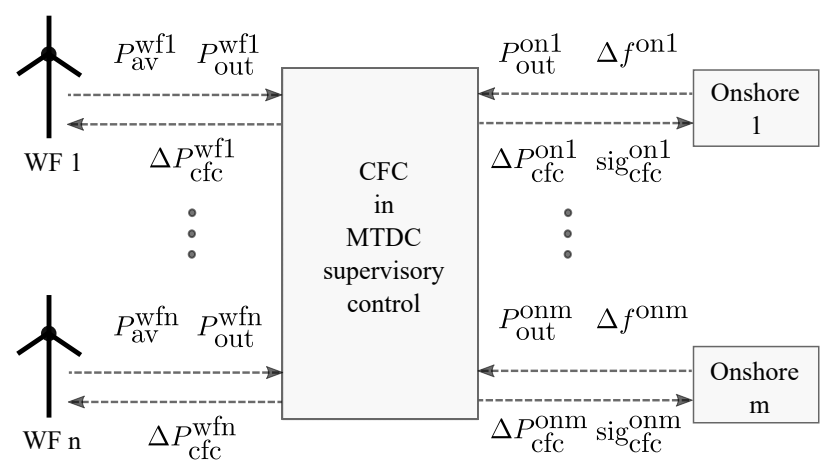

Fig. 4. Centralized frequency control (CFC) is embedded in the offshore HVDC grid supervisory control.

The power-change of both onshore converters is

$$
\begin{aligned}
& \Delta P_{1}=\frac{-\left(k_{\mathrm{v} 2}+k_{\mathrm{v} 3}\right) k_{\mathrm{f} 1}}{k_{\mathrm{v} 1}+k_{\mathrm{v} 2}+k_{\mathrm{v} 3}} \Delta f \\
& \Delta P_{3}=\frac{k_{\mathrm{v} 3} k_{\mathrm{f} 1}}{k_{\mathrm{v} 1}+k_{\mathrm{v} 2}+k_{\mathrm{v} 3}} \Delta f
\end{aligned}
$$

It is clear that $\Delta P_{1}$ is more than $\Delta P_{2}$, which means converter $\mathrm{B}$ reacts in adverse. As a result, some power, $\Delta P_{3}$, circulates among the shore converters, which is not desired and can cause problems such as lines and converters overloading, affecting power-flow between areas, and so on.

\section{J. Other Challenges of Using AFC}

Interaction between $\mathrm{AFC}$ and dc voltage protection system is another concern, which has been addressed in [4]. Adding to the complexity of tuning the voltage and frequency droops at different terminals is also a concern when using AFC in dc grids [4]. There might be other challenges related to AFC in offshore dc grids that have not been identified in this paper.

\section{Proposed Comprehensive Frequency Control}

According to the identified challenges regarding AFC in offshore dc grid, it does not seem to be a promising solution neither from technical nor from the regulatory perspective. The ENTSO-E grid code requires fast communication between offshore and onshore HVDC stations for frequency control [25], which means the current standard does not rely on AFC. However, the AFC can assist the system security by increasing the reliability of the whole system. The reliability of offshore systems is crucial as the maintenance cost of offshore installations is considerably high comparing with those of onshore. Using AFC can assist the system reliability in two different ways. First, as shown in Section V-C, the AFC has a positive impact against a converter outage. Second, in the case of communication-based frequency control failure, for any reason, the AFC can take the responsibility of providing support to onshore power system, if needed.

This paper proposes a comprehensive frequency control in which both AFC and CFC are included. The AFC is used as a backup for CFC and also as a protective control scheme for dc-link protection. The CFC, in an HVDC grid, keeps the dc voltage within normal operating limits when the frequency control takes action. This feature makes the backup AFC not to be activated since its operation is based on dc voltage deviation.

The schematic diagram of CFC embedded in the supervisory control of an offshore HVDC grid is shown in Fig. 4. The supervisory control requires different types of information to implement the CFC. These information include grid codes and frequency deviations $\left(\Delta f^{\text {on }}\right)$ of the land systems, line and converters' limits, power flow through HVDC terminals $\left(P_{\text {out }}^{\mathrm{wf}}\right.$ and $\left.P_{\mathrm{out}}^{\mathrm{on}}\right)$, available power of wind farms $\left(P_{\mathrm{av}}^{\mathrm{wf}}\right)$, power market bids, and so on. Based on such information, the CFC distributes the frequency-supportive power among selected terminals by sending corresponding signals, i.e., $\Delta P_{\mathrm{cfc}}^{\mathrm{wf}}$ to wind farms and $\Delta P_{\mathrm{cfc}}^{\mathrm{on}}$ to the land HVDC converters. The $\Delta P_{\mathrm{cfc}}^{\mathrm{on}}$ is the amount of active power that one onshore converter supplies to another disturbed onshore ac system.

If an onshore ac system contributes to the frequency control of another onshore grid, its frequency control is deactivated by signal $\mathrm{sig}_{\mathrm{cfc}}^{\mathrm{on}}$, which is communicated from CFC. The proposed frequency control for onshore converters is shown in Fig. 5. There is a switch in the control system, which determines whether the converter controls its own frequency or participates in another onshore network frequency control, respectively by holding 1 or 0 positions. In case of the latter, if there is a significant deviation in the local frequency, the converter is discharged from supporting other ac grid, i.e., the output of LFD (large frequency deviation) block will be 1. The offshore HVDC converters use dc voltage-frequency droop control as shown in Fig. 6. On the turbine level, also shown in Fig. 6, a signal from CFC, $\Delta P_{\text {cfc }}$, is used in parallel with frequency droop, which is a part of AFC.

The reserve power dispatch in CFC is fulfilled as shown in Fig. 7. Using the CFC, a disturbed onshore system can receive support from all contracted offshore wind farms and other onshore ac systems. The contracted offshore wind farms or onshore systems participate in reserve market and sell reserves to a certain power system. For example, in Fig. 7, offshore wind farms promise to provide maximum reserve power of $\mathrm{PR}_{\mathrm{wf1}}^{\mathrm{on} 1} \ldots \mathrm{PR}_{\mathrm{wfn}}^{\mathrm{on1}}$ with the gain of $k_{\mathrm{wf} 1}^{\mathrm{on} 1} \ldots k_{\mathrm{wfn}}^{\mathrm{on} 1}$ to onshore 1 in case of frequency disturbance. The other onshore systems, if contracted, can also sell maximum reserve of $\mathrm{PR}_{\mathrm{on} 2}^{\mathrm{on}} \ldots \mathrm{PR}_{\mathrm{onm}}^{\mathrm{on} 1}$ with the gain of $k_{\mathrm{on} 2}^{\mathrm{on} 1} \ldots k_{\mathrm{onm}}^{\mathrm{on} 1}$ to system 1 . Should for any reason-components outage or not participating in reserve market - an offshore wind farm or other ac systems cannot provide support to a disturbed system, its corresponding signal (e.g. $\operatorname{sig}_{\mathrm{wf} 1}^{\mathrm{on} 1} \ldots \operatorname{sig}_{\mathrm{wfn}}^{\mathrm{on} 1}$ or $\operatorname{sig}_{\mathrm{on} 2}^{\mathrm{on1}} \ldots \operatorname{sig}_{\mathrm{onm}}^{\mathrm{on} 1}$ ) becomes zero, otherwise it is one. A disturbed onshore is not allowed to participate in supporting other disturbed systems by making its corresponding signal zero; for example, if onshore 1 is disturbed then $\mathrm{flg}_{1}=0$.

The total amount of reserve power that each offshore wind farm can provide is calculated as

$$
\Delta P_{\mathrm{cfc}}^{\mathrm{wf} 1}=\sum_{i=1}^{\mathrm{m}} \Delta P_{\mathrm{wf} 1}^{\mathrm{on} i}, \ldots, \Delta P_{\mathrm{cfc}}^{\mathrm{wfn}}=\sum_{i=1}^{\mathrm{m}} \Delta P_{\mathrm{wfn}}^{\mathrm{on} i}
$$

where $\Delta P_{\mathrm{wf1}}^{\mathrm{on} i} \ldots \Delta P_{\mathrm{wfn}}^{\mathrm{on} i}$ are generated by CFC shown in Fig. 7. Similarly, the amount of reserve power than one onshore 


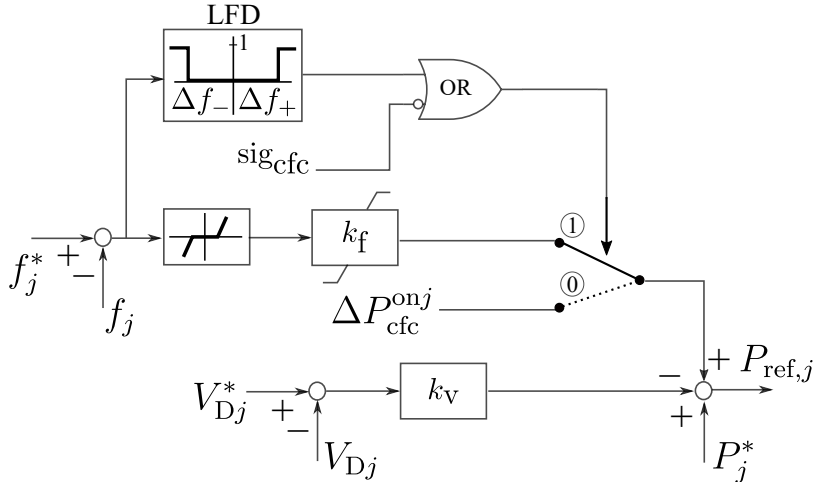

Fig. 5. Proposed frequency control for HVDC converter on onshore $j$. Signals $\operatorname{sig}_{\mathrm{cfc}}$ and $\Delta P_{\mathrm{cfc}}^{\mathrm{on} j}$ are provided by the CFC in (12).

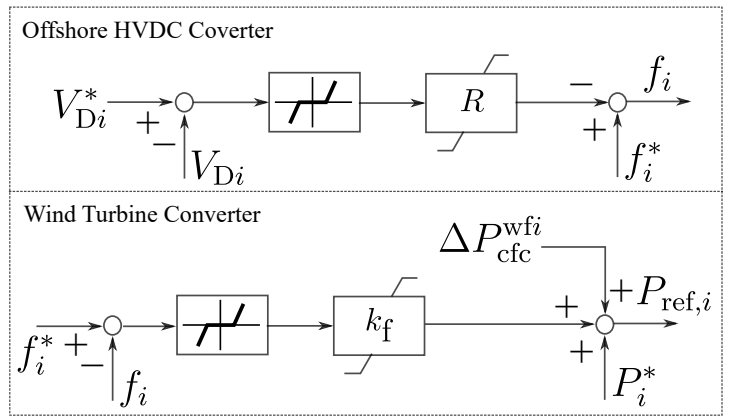

Fig. 6. Proposed frequency control for offshore HVDC and wind turbine converters in wind farm $i . \Delta P_{\mathrm{cfc}}^{\mathrm{wf} i}$ (in per-unit) is provided by the CFC in (11).

grid can provide to other disturbed onshore grids is calculated as

$$
\begin{aligned}
\Delta P_{\mathrm{cfc}}^{\mathrm{on} 1} & =\sum_{i=2}^{\mathrm{m}} \Delta P_{\mathrm{on} 1}^{\mathrm{on} i}, \Delta P_{\mathrm{cfc}}^{\mathrm{on} 2}=\sum_{i=1, i \neq 2}^{\mathrm{m}} \Delta P_{\mathrm{on} 2}^{\mathrm{on} i}, \ldots, \\
\Delta P_{\mathrm{cfc}}^{\mathrm{onm}} & =\sum_{i=1}^{\mathrm{m}-1} \Delta P_{\mathrm{onm}}^{\mathrm{on} i}
\end{aligned}
$$

The parameters $k_{\mathrm{wf} j}^{\mathrm{on} i}$ are chosen by the transmission system operators (TSOs) as they do with the conventional generators equipped with primary reserve. The parameters $k_{\mathrm{on} j}^{\mathrm{on} i}$ are chosen by two TSOs that want to trade the primary reserve. The $k_{\mathrm{f}}$ for onshore converter $i$ shown in Fig. 5 can be calculated as

$$
k_{\mathrm{f}, i}=\sum_{j=1}^{n} k_{\mathrm{wf} j}^{\mathrm{on} i} \operatorname{sig}_{\mathrm{wf} j}^{\mathrm{on} i}+\sum_{k=1, k \neq i}^{m} k_{\mathrm{on} k}^{\mathrm{on} i} \mathrm{flg}_{\mathrm{k}} \operatorname{sig}_{\mathrm{on} k}^{\mathrm{on} i}
$$

and for offshore wind farms the $k_{\mathrm{f}}$ cannot be precisely calculated as for onshore converters. However, it can be estimated, for example for offshore $i$, as

$$
\min \left\{k_{\mathrm{wf} i}^{\mathrm{on} 1} \ldots k_{\mathrm{wf} i}^{\mathrm{on} m}\right\}<k_{\mathrm{f}, i} \leq \sum_{j=1}^{n} k_{\mathrm{wf} i}^{\mathrm{on} j} \operatorname{sig}_{\mathrm{wf} i}^{\mathrm{on} j}
$$

The dc-link voltage control gains, $k_{\mathrm{v}}$ in Fig. 5 and $R$ in Fig. 6, are determined based on the system performance and stability, which has been excessively studied in the literature [26], [28]-[30].

To illustrate how the proposed frequency control works, an example is given using the HVDC grid topology shown in Fig. 1. Assume that there is a frequency disturbance on shore A, $\Delta f_{1}$, and all its expected power, i.e., $k_{\mathrm{f} 1} \Delta f_{1}$, should be supplied to satisfy the grid code requirement. The required power is assumed to be supplied from shore $\mathrm{B}$, by $\alpha$ per-cent, and offshore $\mathrm{C}$, by $\beta$ per-cent, i.e., $\alpha+\beta=1$. Accordingly, in CFC algorithm, shown in Fig. $7, k_{\mathrm{wf} 2}^{\mathrm{on} 1}=1, k_{\mathrm{wf} 4}^{\mathrm{on} 1}=0$ and $k_{\mathrm{on} 3}^{\mathrm{on} 1}=$ 1. The CFC sends $\Delta P_{\mathrm{cfc}}^{\mathrm{wf} 2}=\alpha k_{\mathrm{f} 1} \Delta f_{1}$ and $\Delta P_{\mathrm{cfc}}^{\mathrm{on} 3}=\beta k_{\mathrm{f} 1} \Delta f_{1}$ respectively to offshore $\mathrm{C}$ and onshore $\mathrm{B}$. Since the converter $\mathrm{B}$ participates in the frequency control of shore A, its own local frequency control is deactivated. Therefore, $\operatorname{sig}_{\mathrm{cfc}}^{\text {on3 }}=1$ and also $\operatorname{sig}_{\mathrm{cfc}}^{\text {on1 }}=0$. Based on such assumptions and also control schemes shown in figures 4,5 and 6 , the control function of the converters can be stated as

$$
\begin{aligned}
& \Delta P_{1}=-k_{\mathrm{v} 2} \Delta V_{\mathrm{D} 2}-k_{\mathrm{f} 1} \Delta f_{1} \\
& \Delta P_{2}=-k_{\mathrm{v} 2} \Delta V_{\mathrm{D} 2}-\alpha k_{\mathrm{f} 1} \Delta f_{1} \\
& \Delta P_{3}=+k_{\mathrm{v} 3} \Delta V_{\mathrm{D} 3}+\beta k_{\mathrm{f} 1} \Delta f_{1}
\end{aligned}
$$

Assuming loss-less de transmission, and constant power supply from offshore $\mathrm{D}$, the power flow in the dc grid will be $\Delta P_{2}=\Delta P_{1}+\Delta P_{3}$. Considering this power flow in (15) results in

$$
\Delta P_{1}=-\alpha k_{\mathrm{f} 1} \Delta f_{1}-\beta k_{\mathrm{f} 1} \Delta f_{1}=-k_{\mathrm{f} 1} \Delta f_{1}
$$

which shows that the expected power can be supplied to the disturbed ac system. In (15) the dc voltage deviation is zero and the backup AFC is not activated. This fact is also shown in simulation results where the transmission losses are not neglected. The slight mismatch between $k_{\mathrm{f} 1} \Delta f_{1}$ and $\Delta P_{\mathrm{cfc}}^{\mathrm{wf} 2}+$ $\Delta P_{\mathrm{cfc}}^{\mathrm{on}}$, which is caused by dc link losses can be compensated by the CFC.

The voltage droop gains, $k_{\mathrm{v}}$, in the proposed control can be determined based on desired power sharing and converter outage considerations [26], [31]. The onshore frequency droop gains, the inverse of $k_{\mathrm{f}}$, are determined by the system operators, based on an agreement .

Although the AFC is not operational in most of the time, using it as a backup can be beneficial. One of the benefits is that the AFC can contribute to dc voltage control when one of the onshore converters trips. When an importing converter trips, the dc voltage rises and the remaining land converters should maintain the dc voltage. However, these converters may reach to their power or current limits, and consequently, the dc voltage can be left uncontrolled. The fast and automatic power-reduction of wind farms, made by AFC, helps to return the dc voltage to its safety limits. The other advantage of using the AFC in backup is increasing the system reliability. For any reason when the CFC fails, the AFC can take over the frequency control; although not optimal because of the issues identified in this paper, but it regulates the power flow such that the system security is enhanced.

The CFC not only can be used for primary frequency control, but also for secondary service. This implies that by downward regulation, wind farms can simultaneously benefit from selling primary and secondary services. 

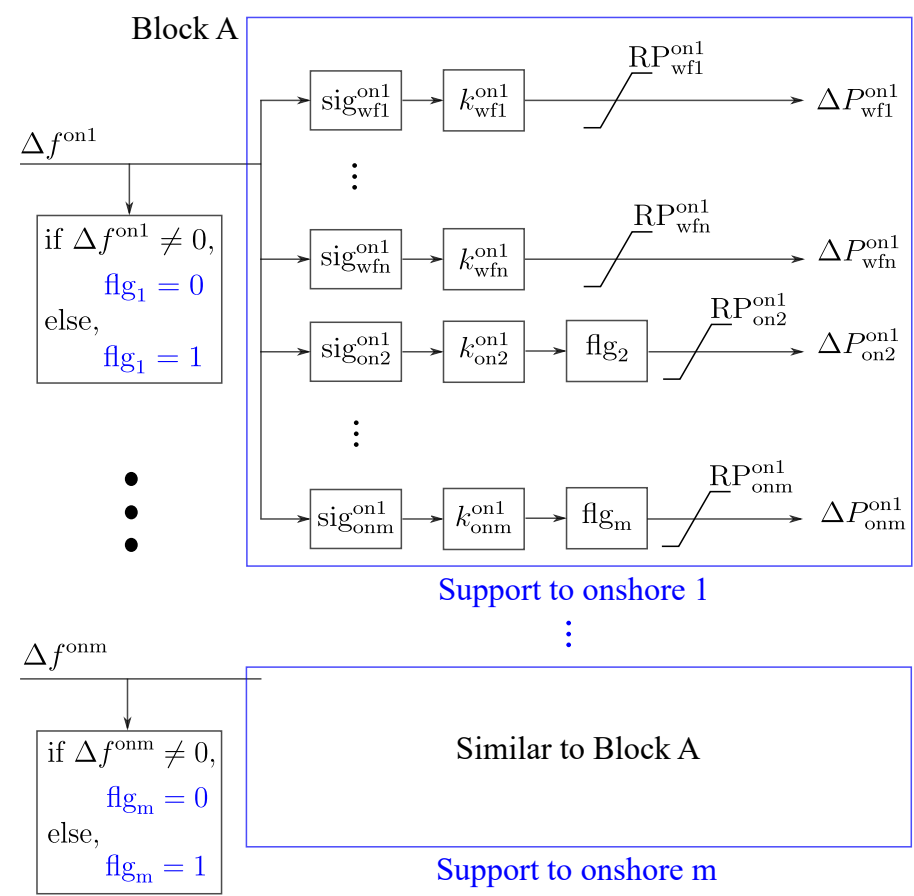

Fig. 7. Reserve power dispatch among onshore and offshore system in CFC.

\section{Simulation Results}

Different case studies are simulated on the offshore HVDC, shown in Fig. 1. Simulation results show how the proposed control overcomes the deficiencies of AFC, which were identified in Section III. It is assumed that both offshore wind farms contribute in frequency control and onshore converters use dc voltage droop. Since the onshore converters control the dc voltage, their voltage bias (inverse of droop) is chosen higher, i.e., $k_{\mathrm{v} 1}=10$ and $k_{\mathrm{v} 3}=8 \mathrm{pu}$. The base values for power and dc-link voltage are respectively $1000 \mathrm{MW}$ and 640 $\mathrm{kV}$.

The nominal generation capacity of offshore C and D are respectively 1000 and $800 \mathrm{MW}$ and their outputs for an operating point are 800 and $700 \mathrm{MW}$. The wind farms curtail their generation to participate in onshore frequency support. Under steady state operation, it is planned that $950 \mathrm{MW}$ is exported to onshore A, and $550 \mathrm{MW}$ to onshore $\mathrm{B}$.

For each onshore system a synchronous machine equipped with turbine, governor, and AVR has been considered plus passive loads connected to the generators via transformer and ac transmission lines. The synchronous generators have their field and one damper winding on their d-axis and two damper winding on their q-axis. Hydro-turbine governing system is used as prime mover for the synchronous generators. All component and controller parameters used for simulations are provided in the Appendix.

Measuring onshore frequencies, low-pass filters with a time constant of 50 milliseconds are used. These filters together with the hard-limiters, applied on frequency droop, prevent the reflection of transient phenomenon such as onshore ac faults into frequency control loops. Moreover, these low-pass filters
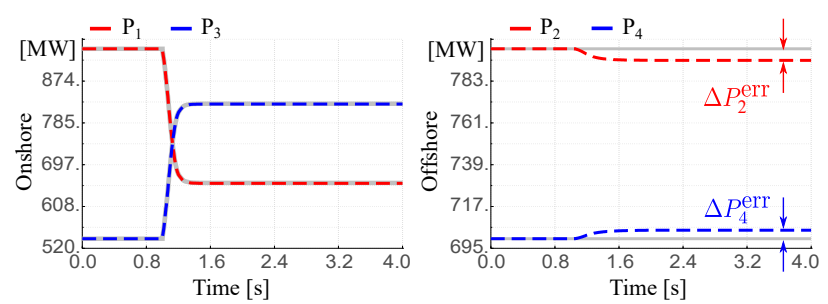

Fig. 8. Power in HVDC terminals when 200 MW shifts from converter A to B. Plots in color are the result from AFC, and those in gray from the proposed controller.

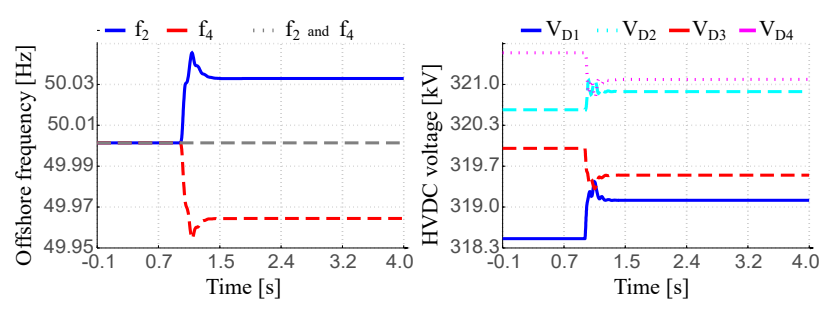

Fig. 9. Voltage in HVDC terminals when 200 MW shifts from converter A to B. Plots in color are the result from AFC, and those in gray from the proposed controller.

further decrease the dynamic interactions between frequency and other control loops of an HVDC grid.

\section{A. Change in Operating Point}

The onshore grids can trade the power through HVDC network. It is decided that shore A decreases $200 \mathrm{MW}$ of its import from offshore wind to be exported to shore B. Without communication between the shore grids this power trade cannot be done accurately because of the droop control on onshore converters. Although using communication, the presence of AFC causes the adverse reaction of the wind farms. As shown in Fig. 8, changing the onshore power, offshore wind farms experience error in their power respectively by $\Delta P_{2}^{\text {err }}$ and $\Delta P_{4}^{\text {err }}$. The reason of such undesired reaction is that the distance between onshore grids is far, in comparison, and a power change between the land grids require larger change in the both onshore terminals. The offshore terminals can detect the voltage-change and react with altering their active power. Figure 9 shows the offshore frequencies and $\mathrm{dc}$ voltage on four terminals. Since the farm $\mathrm{C}$ is closer to shore $\mathrm{A}$, and farm $\mathrm{D}$ to shore $\mathrm{B}$, their voltage change are in opposite direction, and therefore their frequencies change differently. In the proposed controller the voltage dead-band of offshore converters is higher, $0.01 \mathrm{pu}$; thereby, the adverse reaction of the farms are not observed. This fact is evident from the gray-color plots in Fig. 8 and 9.

As another scenario of a change in operating, the offshore $\mathrm{C}$ increases instantly its output power by $150 \mathrm{MW}$. This type of instant significant change in a wind farm output is somehow unlikely in practice, but for the sake of visibility of the error caused by AFC, this type of change has been considered in this scenario. The power flow of HVDC terminals for this case is shown in Fig. 10. The error of offshore D, $\Delta P_{4}^{\text {err }}$, is the result of the feedback loop that is described in Section 

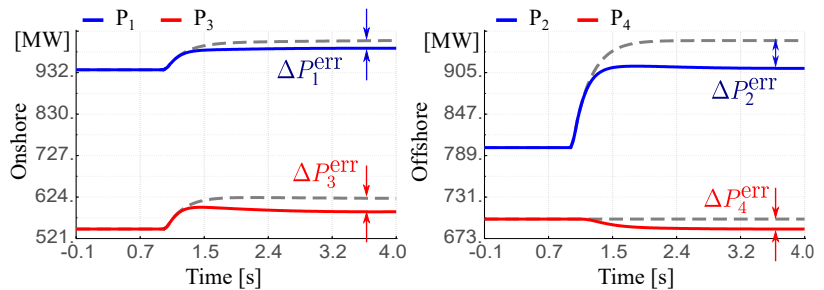

Fig. 10. Power in HVDC terminals when offshore $C$ increases $150 \mathrm{MW}$ of its power. Plots in color are the result from AFC, and those in gray from the proposed controller.

III-C. The error plus the adverse reaction of offshore D result in inaccurate power sharing of the land converters which experience $\Delta P_{1}^{\text {err }}$ and $\Delta P_{3}^{\text {err }}$. Similar to the previous scenario, the proposed control uses higher dc voltage dead-band on offshore converters, and therefore does not experience such error as shown in gray in Fig. 10.

It should be noted that in both of the examples of operating point change, the frequency control from onshore converters are deactivated since the power changes are scheduled.

\section{B. Onshore Frequency Support}

An unbalance between generation and consumption has been created on onshore A, which results in a frequency drop as shown in Fig. 11. Converter A uses a frequency droop of $0.05 \mathrm{pu}$, and the supportive power has been planned to be supplied from other terminals as 50\% from offshore C, $30 \%$ from offshore D, and 20\% from ac system B. Although the frequency of onshore A has been improved by using the AFC, it is still lower than what is required by the corresponding TSO. This implies that expected power cannot be delivered to ac system A as observed in Fig. 12. Moreover, the distribution of the supportive power is not what has been planned, however, exactly in opposite. The proposed control has been able to export the required power to shore $\mathrm{A}$ with the scheduled power distribution among other converters. As shown in Fig. 13, dc voltages at HVDC terminals have smaller deviation, when using the proposed control.

For the proposed control, a communication delay of $50 \mathrm{~ms}$ has been considered. It is also assumed that sampling time of wind farms supervisory control is $150 \mathrm{~ms}$. Since even in the proposed method AFC reacts immediately, the transient behaviour of the system, as shown in Fig. 11, 12, and 13, is the same for AFC and the proposed method, regardless of communication delay and wind farm sampling time.

\section{Onshore Converter Outage}

To show an advantage of AFC as part of the proposed control, its protective reaction against onshore ac fault is investigated by means of simulation results. The worst case of an onshore ac fault can result in outage of an onshore HVDC converter. It is assumed that converter B trips, under a severe ac fault, and all offshore power flows to converter A whose maximum power capacity is $1200 \mathrm{MW}$. As a result, converter A saturates and the dc voltage is left uncontrolled in the case the offshore wind farms keep operating with constant power.

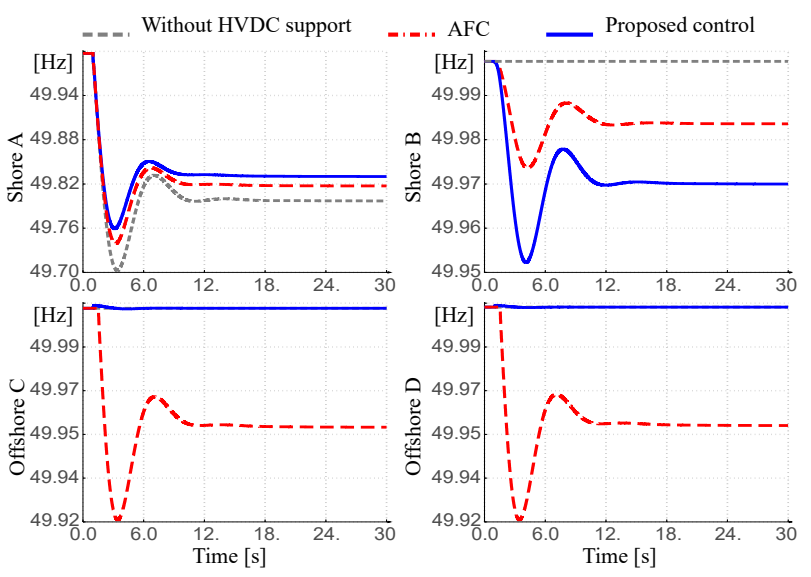

Fig. 11. AC systems' frequencies when there is a generationconsumption unbalance on shore A.
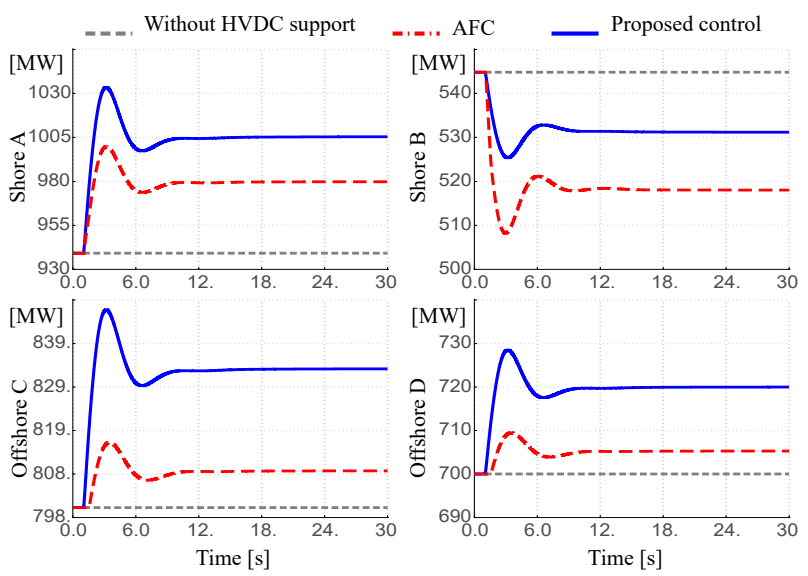

Fig. 12. Power flow of HVDC converters when there is a generation-consumption unbalance on shore A.

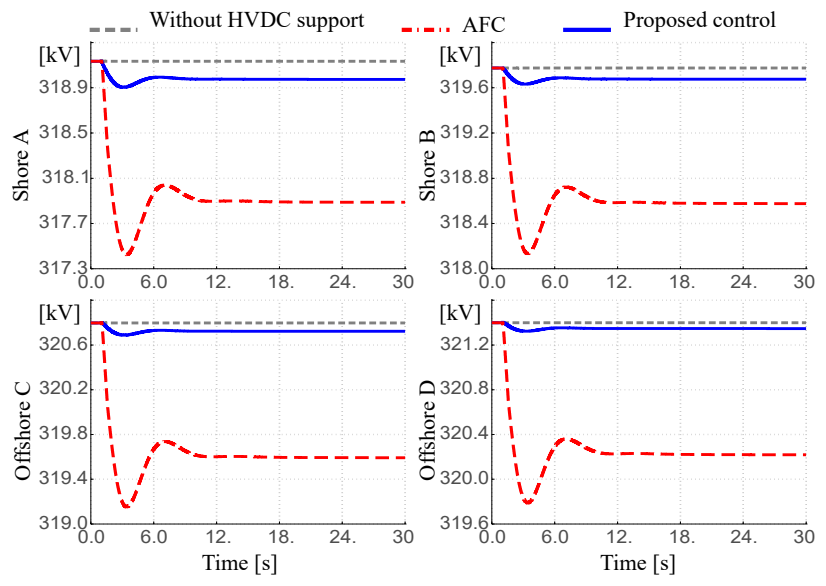

Fig. 13. DC grid voltages when there is a generationconsumption unbalance on shore A.

Total power from wind farms is $1500 \mathrm{MW}$ while the output is $1200 \mathrm{MW}$. This imbalance gives a significant rise to dc voltage as shown in Fig. 14. In case of AFC, however, the dc voltage returns back to a bounded value after a transient. The dc voltage protection system is intentionally deactivated to show the pure reaction of the AFC. For this reason, the 

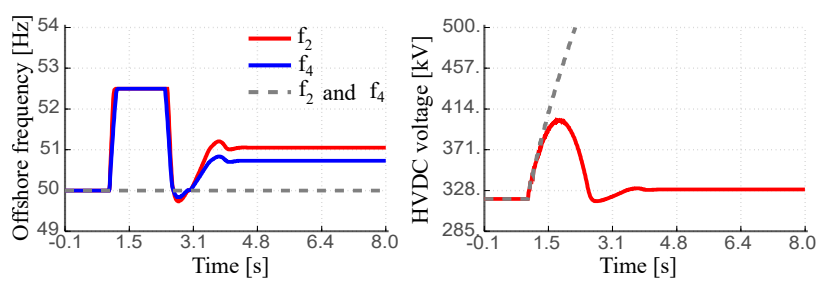

Fig. 14. Offshore frequencies and dc voltage when the converter B trips. Plots in gray show the case without offshore reactions.
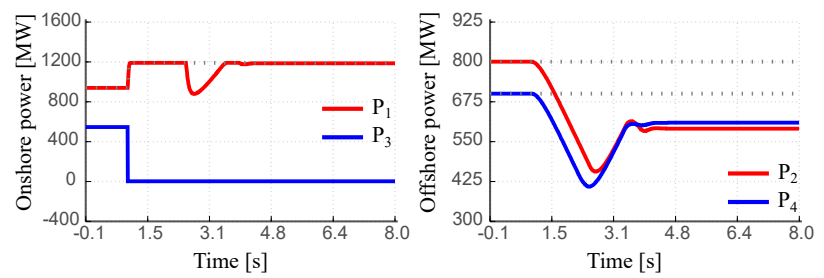

Fig. 15. Power flow in onshore and offshore when the converter B trips. Plots in gray show the case without offshore reactions.

dc-link voltage excursion, seen in Fig. 14, is significant even in case of AFC operation. To consider more realistic reaction of the AFC to a converter outage, the limitations of OWFs power and frequency in terms of amplitude and speed of change have been taken into account. A ramp rate limiter of power, $500 \mathrm{MW} / \mathrm{sec}$, as well as frequency limit $(52.5 \mathrm{~Hz})$ are considered for the wind farms. These considerations result in temporary increase of dc voltage. Offshore frequency, dc voltage variations, and active power of HVDC converters are shown in Fig. 14 and 15. It must be noted that dc-link voltage protection is not the main responsibility of the AFC, but an add-on benefit. More protective scheme against a converter outage in an HVDC grid can be found in [32].

\section{CONCLUSIONS}

The autonomous (communication less) frequency control (AFC) has been designed for point-to-point connections. However, the AFC for frequency response and control of adjacent ac grids become exhausted when applied for the HVDC grids. This paper has confirmed technical and regulatory issues concerning the feasibility and required controllability arising from utilization of the AFC in offshore HVDC grids. It is concluded that the AFC type of control does not pave the way for dc-connected offshore wind farms, as individual, notcoordinated, participants, to play in the power capacity market. Further, this paper has confirmed the AFC causing interactions between frequency and dc voltage droop control, which results in operation difficulties and control conflicts within the HVDC grids. To tackle the challenges of AFC, this paper proposed a comprehensive frequency control utilizing a centralized frequency control (CFC) in parallel with AFC. The proposed comprehensive control utilizes the $\mathrm{CFC}$ as the main controller and the AFC locally as a backup for unforeseen misfunctions within the CFC or forced outages of the HVDC stations.
Should for any reason CFC fails, the AFC immediately takes over and temporarily supports the disturbed ac system to some extent. Moreover, the immediate reaction of AFC can be useful in maintaining the dc-link voltage in case of outage of a single onshore converter. The paper has demonstrated by simulations that the comprehensive frequency control using AFC together with CFC create shall satisfy both grid code and market requirements, and boosts the overall HVDC wind power system security.

\section{APPENDIX}

Parameters of the components and controllers used for the studied system, shown in Fig. 1, are given in this section.

TABLE I

CONTROLLER AND COMPONENT PARAMETERS OF VSC A

\begin{tabular}{lll}
\hline Active power control & $k_{\mathrm{p}}=10$ & $k_{\mathrm{i}}=100$ \\
Reactive power control & $k_{\mathrm{p}}=12$ & $k_{\mathrm{i}}=100$ \\
Droops & $k_{\mathrm{v} 1}=10$ & $k_{\mathrm{f} 1}=20$ \\
Inner current control & $k_{\mathrm{p}}=2$ & $k_{\mathrm{i}}=500$ \\
MMC submodule & No. $=200$ per arm & $C=10 \mathrm{mF}$ \\
Arm reactor & $R=0.006 \mathrm{Ohm}$ & $L=60 \mathrm{mH}$ \\
\hline
\end{tabular}

TABLE II

CONTROLLER AND COMPONENT PARAMETERS OF VSC B

\begin{tabular}{lll}
\hline Active power control & $k_{\mathrm{p}}=10$ & $k_{\mathrm{i}}=100$ \\
Reactive power control & $k_{\mathrm{p}}=12$ & $k_{\mathrm{i}}=100$ \\
Droops & $k_{\mathrm{v} 3}=8$ & $k_{\mathrm{f} 3}=15$ \\
Inner current control & $k_{\mathrm{p}}=2$ & $k_{\mathrm{i}}=500$ \\
MMC submodule & No. $=200 \mathrm{per}$ arm & $C=10 \mathrm{mF}$ \\
Arm reactor & $R=0.006 \mathrm{Ohm}$ & $L=60 \mathrm{mH}$ \\
\hline
\end{tabular}

TABLE III

CONTROLlER AND COMPONENT PARAMETERS OF VSC C

\begin{tabular}{lll}
\hline AC voltage control & $k_{\mathrm{p}}=2$ & $k_{\mathrm{i}}=5$ \\
Droops & $R_{2}=0.75$ & $V_{\mathrm{dc}}$ deadband $=0.01 \mathrm{pu}$ \\
Inner current control & $k_{\mathrm{p}}=2$ & $k_{\mathrm{i}}=50$ \\
MMC submodule & No. $=200$ per arm & $C=10 \mathrm{mF}$ \\
Arm reactor & $R=0.006 \mathrm{Ohm}$ & $L=60 \mathrm{mH}$ \\
\hline
\end{tabular}

TABLE IV

CONTROLLER AND COMPONENT PARAMETERS OF VSC D

\begin{tabular}{lll}
\hline AC voltage control & $k_{\mathrm{p}}=2$ & $k_{\mathrm{i}}=5$ \\
Droops & $R_{4}=0.5$ & $V_{\mathrm{dc}}$ deadband $=0.01 \mathrm{pu}$ \\
Inner current control & $k_{\mathrm{p}}=2$ & $k_{\mathrm{i}}=50$ \\
MMC submodule & No. $=200$ per arm & $C=10 \mathrm{mF}$ \\
Arm reactor & $R=0.006 \mathrm{Ohm}$ & $L=60 \mathrm{mH}$ \\
\hline
\end{tabular}

TABLE V

ONSHORE LUMPED GENERATOR PARAMETERS

\begin{tabular}{llll}
\hline Gen. of onshore A & $\mathrm{S}=10000 \mathrm{MVA}$ & $\mathrm{H}=10 \mathrm{~s}$ & $\mathrm{U}=15.75 \mathrm{kV}$ \\
& $x_{\mathrm{d}}^{\prime \prime}=x_{\mathrm{q}}^{\prime \prime}=0.2 \mathrm{pu}$ & $x_{\mathrm{d}}^{\prime}=x_{\mathrm{q}}^{\prime}=0.3 \mathrm{pu}$ & $x_{1}=0.17 \mathrm{pu}$ \\
Gen. of onshore B & $\mathrm{S}=5000 \mathrm{MVA}$ & $\mathrm{H}=5 \mathrm{~s}$ & $\mathrm{U}=15.75 \mathrm{kV}$ \\
& $x_{\mathrm{d}}^{\prime \prime}=x_{\mathrm{q}}^{\prime \prime}=0.2 \mathrm{pu}$ & $x_{\mathrm{d}}^{\prime}=x_{\mathrm{q}}^{\prime}=0.3 \mathrm{pu}$ & $x_{1}=0.17 \mathrm{pu}$ \\
\hline
\end{tabular}


TABLE VI

TURBINE AND GOVERNOR PARAMETERS USED FOR ONSHORE GENERATORS

Gen. A Gain $=200 \mathrm{MW} / \mathrm{Hz} \quad$ Type in Powerfactory $=$ gov_HYGOV2

Gen. B Gain $=100 \mathrm{MW} / \mathrm{Hz} \quad$ Type in Powerfactory $=$ gov_HYGOV2

The other parameters, except the gain, such filters time constants and gains of governor and turbines are kept as default values in the Powerfactory tool.

TABLE VII

SUBMARINE DC CABLE PARAMETERS

Reactance $X^{\prime}=0.4 \mathrm{Ohm} / \mathrm{km} \quad$ Capacitance $C^{\prime}=0.01 \mathrm{uF} / \mathrm{km}$

Resistance $R^{\prime}\left(20^{\circ}\right)=0.01 \mathrm{Ohm} / \mathrm{km} \quad$ Resistance $R^{\prime}\left(80^{\circ}\right)=0.0187 \mathrm{Ohm} / \mathrm{km}$

Model $=$ Distributed parameters

TABLE VIII

PARAMETERS OF OWF B

\begin{tabular}{lll}
\hline WTs & No. $=200 \mathrm{WTs}$ & Nominal power $=5 \mathrm{MW}$ \\
Active power control & $k_{\mathrm{p}}=0.1$ & $k_{\mathrm{i}}=5$ \\
Reactive power control & $k_{\mathrm{p}}=0.5$ & $k_{\mathrm{i}}=25$ \\
Frequency droop $k_{\mathrm{f} 2}=0.1$ & phase reactor $X_{\mathrm{ph}}=10 \%$ & \\
\hline
\end{tabular}

TABLE IX

PARAMETERS OF OWF D

\begin{tabular}{lll}
\hline WTs & No. $=100 \mathrm{WTs}$ & Nominal power $=8 \mathrm{MW}$ \\
Active power control & $k_{\mathrm{p}}=0.1$ & $k_{\mathrm{i}}=5$ \\
Reactive power control & $k_{\mathrm{p}}=0.5$ & $k_{\mathrm{i}}=25$ \\
Frequency droop $k_{\mathrm{f} 2}=0.16$ & phase reactor $X_{\mathrm{ph}}=10 \%$ & \\
\hline
\end{tabular}

TABLE X

PARAMETERS OF TRANSFORMERS

\begin{tabular}{llll}
\hline Step-up Trans. A & No. of trans. $=10$ & $S_{\text {rated }}=1000 \mathrm{MVA}$ & $15.75 / 230 \mathrm{kV}$ \\
VSC Trans. A & No. of trans. $=1$ & $S_{\text {rated }}=1200 \mathrm{MVA}$ & $230 / 333.6 \mathrm{kV}$ \\
Step-up Trans. B & No. of trans. $=5$ & $S_{\text {rated }}=1000 \mathrm{MVA}$ & $15.75 / 230 \mathrm{kV}$ \\
VSC Trans. B & No. of trans. $=1$ & $S_{\text {rated }}=1000 \mathrm{MVA}$ & $230 / 333.6 \mathrm{kV}$ \\
VSC Trans. C & No. of trans. $=1$ & $S_{\text {rated }}=1100 \mathrm{MVA}$ & $66 / 333.6 \mathrm{kV}$ \\
VSC Trans. D & No. of trans. $=1$ & $S_{\text {rated }}=870 \mathrm{MVA}$ & $66 / 333.6 \mathrm{kV}$ \\
WTs Trans. C & No. of trans. $=200$ & $S_{\text {rated }}=5.5 \mathrm{MVA}$ & $0.69 / 66 \mathrm{kV}$ \\
WTs Trans. C & No. of trans. $=100$ & $S_{\text {rated }}=8.7 \mathrm{MVA}$ & $0.69 / 66 \mathrm{kV}$ \\
\hline
\end{tabular}

\section{REFERENCES}

[1] European Commission Regulation, "Establishing a network code on requirements for grid connection of high voltage direct current systems and direct currentconnected power park modules," Official Journal of the European Union, no. 112, pp. 1-68, Apr. 2016.

[2] P. Sorknæs, A. N. Andersen, J. Tang, and S. Strøm, "Market integration of wind power in electricity system balancing," Energy Strategy Reviews, vol. 1, no. 3, pp. 174-180, 2013.

[3] WindVision, Enercon, Eneco, and Elia, "Delivery of downward aFRR by wind farms," Tech. Rep., 2015.

[4] Y. Phulpin, "Communication-Free Inertia and Frequency Control for Wind Generators Connected by an HVDC-Link," IEEE Transactions on Power Systems, vol. 27, no. 2, pp. 1136-1137, May 2012.
[5] B. Silva, C. L. Moreira, L. Seca, Y. Phulpin, and J. A. Peças-Lopes, "Provision of Inertial and Primary Frequency Control Services Using Offshore Multiterminal HVDC Networks," IEEE Transactions on Sustainable Energy, vol. 3, no. 4, pp. 800-808, Oct. 2012.

[6] S. Akkari, J. Dai, M. Petit, and X. Guillaud, "Interaction between the voltage-droop and the frequencydroop control for multi-terminal HVDC systems," IET Generation, Transmission \& Distribution, vol. 10, no. 6, pp. 1345-1352, Apr. 2016.

[7] J. N. Sakamuri, M. Altin, A. D. Hansen, and N. A. Cutululis, "Coordinated frequency control from offshore wind power plants connected to multi terminal DC system considering wind speed variation," IET Renewable Power Generation, vol. 11, no. 8, pp. 1226-1236, Jun. 2017.

[8] O. D. Adeuyi, M. Cheah-Mane, J. Liang, and N. Jenkins, "Fast frequency response from offshore multiterminal vsc-hvdc schemes," IEEE Transactions on Power Delivery, vol. PP, no. 99, pp. 1-1, 2017.

[9] T. M. Haileselassie, and K. Uhlen, "Primary Frequency Control of Remote Grids Connected by Multi-terminal HVDC," in IEEE PES General Meeting, Providence, RI, United States, 25-29 Jul. 2010.

[10] J. Zhu, J. M. Guerrero, C. D. Booth, H. Zhang, and G. P. Adam, "A generic inertia emulation controller for multiterminal vsc-hvdc systems," in 2nd IET Renewable Power Generation Conference (RPG 2013), Sep. 2013, pp. 1-6.

[11] A. Bidadfar, O. Saborío-Romano, M. Altin, N. Cutululis, E. Prieto-Araujo, O. Gomis-Bellmunt, and P. Sørensen, "Droop-based frequency support from offshore hvdc grids," English, in Proceedings of the CIGRE Symposium 2019, CIGRE (International Council on Large Electric Systems), 2019.

[12] A. Bidadfar, O. Saborío-Romano, J. N. Sakamuri, M. Altin, N. A. Cutululis, and P. E. Sørensen, "Primary frequency support from offshore wind power plants connected to hvdc grids," in 2019 IEEE Milan PowerTech, Jun. 2019, pp. 1-6. DOI: 10.1109/PTC.2019.8810820.

[13] A. Bidadfar, O. Saborı-Romano, V. Akhmatov, N. A. Cutululis, and P. E. Sørensen, "Impact of primary frequency control of offshore hvdc grids on interarea modes of power systems," Energies, vol. 12, no. 20, p. 3879, 2019.

[14] K. Jose, T. Joseph, J. Liang, and C. E. Ugalde-Loo, "Auxiliary dead-band controller for the coordination of fast frequency support from multi-terminal hvdc grids and offshore wind farms," IET Renewable Power Generation, vol. 12, no. 13, pp. 1444-1452, 2018.

[15] L. Harnefors, N. Johansson, and L. Zhang, "Impact on interarea modes of fast hvdc primary frequency control," IEEE Transactions on Power Systems, vol. 32, no. 2, pp. 1350-1358, Mar. 2017, ISSN: 0885-8950.

[16] F. Díaz-González, M. Hau, A. Sumper, and O. GomisBellmunt, "Participation of wind power plants in system frequency control: Review of grid code requirements and control methods," Renewable and Sustainable En- 
ergy Reviews, vol. 34, pp. 551-564, 2014. DOI: 10.1016/ j.rser.2014.03.040.

[17] Y. G. Rebours, D. S. Kirschen, M. Trotignon, and S. Rossignol, "A survey of frequency and voltage control ancillary services-part i: Technical features," IEEE Transactions on Power Systems, vol. 22, no. 1, pp. 350-357, Feb. 2007.

[18] E. Muljadi, S. Pasupulati, A. Ellis, and D. Kosterov, "Method of Equivalencing for a Large Wind Power Plant with Multiple Turbine Representation," in 2008 IEEE Power and Energy Society General Meeting Conversion and Delivery of Electrical Energy in the 21st Century, Chicago, IL, United States, 20-24 Jul. 2008.

[19] L. Harnefors, M. Bongiorno, and S. Lundberg, "Inputadmittance calculation and shaping for controlled voltage-source converters," vol. 54, no. 6, pp. 33233334, Dec. 2007.

[20] G. O. Kalcon, G. P. Adam, O. A. Lara, S. Lo, and K. Uhlen, "Small-signal stability analysis of multiterminal VSC-based dc transmission systems," vol. 27, no. 4, pp. 1818-1829, Nov. 2012.

[21] N. R. Chaudhuri, B. Chaudhuri, R. Majumder, and A. Yazdani, MULTI-TERMINAL DIRECT-CURRENT GRIDS. 2014, p. 256, ISBN: 9781118729106.

[22] J. Beerten, S. Cole, and R. Belmans, "Modeling of multi-terminal vsc hvdc systems with distributed dc voltage control," IEEE Transactions on Power Systems, vol. 29, no. 1, pp. 34-42, Jan. 2014.

[23] A. Bidadfar, O. Saborío-Romano, M. Altin, N. A. Cutululis, P. E. Sørensen, E. Prieto-Araujo, and O. GomisBellmunt, "Frequency support provision to power systems via hvdc-based offshore wind power plants," English, in 17th Wind Integration Workshop, Stockholm, Sweden, 17-19 Oct. 2018.

[24] T. M. Haileselassie, and K. Uhlen, "Impact of dc line voltage drops on power flow of mtdc using droop control," IEEE Transactions on Power Systems, vol. 27, no. 3, pp. 1441-1449, Aug. 2012.

[25] European Commission Regulation, "Establishing a network code on requirements for grid connection of high voltage direct current systems and direct currentconnected power park modules," Official Journal of the European Union, vol. 59, no. 241, pp. 1-65, Aug. 2016.

[26] E. Prieto-Araujo, F. D. Bianchi, A. Junyent-Ferre, and O. Gomis-Bellmunt, "Methodology for droop control dynamic analysis of multiterminal vsc-hvdc grids for offshore wind farms," IEEE Transactions on Power Delivery, vol. 26, no. 4, pp. 2476-2485, Oct. 2011.

[27] Energinet (Danish System Operator), "Technical regulation 3.2.5 for wind power plants above $11 \mathrm{kw}$," Tech. Rep., 2016.

[28] Y. Li, G. Tang, J. Ge, Z. He, H. Pang, J. Yang, and Y. Wu, "Modeling and damping control of modular multilevel converter based dc grid," IEEE Transactions on Power Systems, vol. 33, no. 1, pp. 723-735, Jan. 2018.
[29] F. Thams, R. Eriksson, and M. Molinas, "Interaction of droop control structures and its inherent effect on the power transfer limits in multiterminal vsc-hvdc," IEEE Transactions on Power Delivery, vol. 32, no. 1, pp. 182192, Feb. 2017.

[30] R. Eriksson, J. Beerten, M. Ghandhari, and R. Belmans, "Optimizing dc voltage droop settings for ac/dc system interactions," IEEE Transactions on Power Delivery, vol. 29, no. 1, pp. 362-369, Feb. 2014.

[31] J. Beerten, and R. Belmans, "Analysis of power sharing and voltage deviations in droop-controlled DC grids," IEEE Transactions on Power Systems, vol. 28, no. 4, pp. 4588-4597, 2013.

[32] R. Eriksson, "Current sharing in multiterminal dc grids - the analytical approach," IEEE Transactions on Power Systems, vol. 33, no. 6, pp. 6278-6288, Nov. 2018, ISSN: 1558-0679.

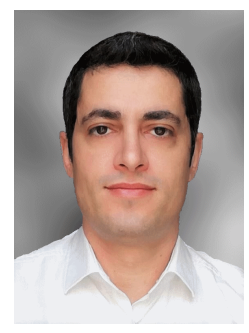

Ali Bidadfar (M'14) worked as a power system researcher at KTH, Stockholm, Sweden, from 2013 to 2016. He has been a $\mathrm{PhD}$ researcher at the Technical University of Denmark since 2016. During his PhD, he has focused on frequency support provision from offshore HVDC grids. In August 2019, he joined Ørsted, Copenhagen, Denmark, as a power system engineer. His research interests include HVDC control and operation, offshore wind generation and transmission technologies, control and stability of power systems.

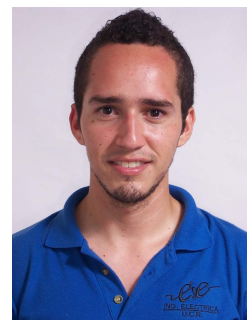

Oscar Saborío-Romano (S'12) received the BSc (Hons) degree in Electrical Engineering from the University of Costa Rica in 2013. In 2015, he received the MSc degrees in Electrical Engineering and Wind Energy from Delft University of Technology and the Norwegian University of Science and Technology, respectively. He joined the Department of Wind Energy at the Technical University of Denmark in 2016, where he is currently pursuing a PhD. His research interests include power system control and stability, integration of renewable energy sources, modelling and control of wind power, HVDC transmission, and microgrids.

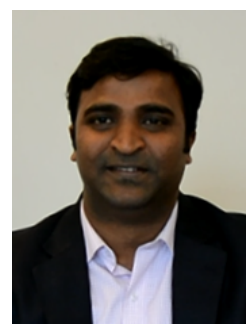

Jayachandra N. Sakamuri received the MTech degree in Electrical Engineering from the Indian Institute of Technology in 2009, after spending a year as an exchange student at the Technical University of Berlin, Germany, in 2008. He received the $\mathrm{PhD}$ degree on Coordinated Control of Wind Power Plants in Offshore HVdc Grids from DTU Wind Energy. Before the $\mathrm{PhD}$, he worked for Grid System R\&D, ABB on HVdc System Design for three years and also at Crompton Greaves Ltd. on HV switchgear design. His research interests include HVDC, offshore WPP integration and control, and HV switchgear design. 


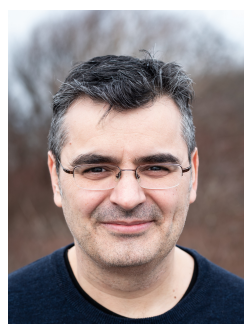

Nicolaos A. Cutululis (SM'18) received the MSc and $\mathrm{PhD}$ degrees, both in Automatic Control, in 1998 and 2005, respectively. Currently, he is a professor at the Department of Wind Energy, Technical University of Denmark. His main research interests are integration of wind power, with a special focus on offshore wind power, and grids.

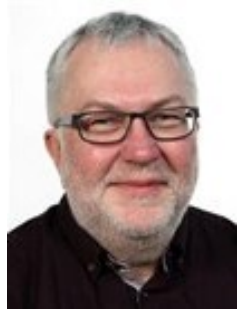

Poul E. Sørensen (SM'07) is professor in wind power integration and control in the Department of Wind Energy at the Technical University of Denmark. He was born in 1958 and received M.Sc. degree in electrical engineering from DTU in 1987. $\mathrm{He}$ is convener of IEC 61400-27 electrical simulation models for wind power generation. $\mathrm{He}$ is also principal investigator and work package leader in a number of research projects and has supervised $20 \mathrm{PhD}$ students and 30 Master thesis. He has been senior member since 2007 . 